\title{
Impact of UNESCO Heritage Status on Japanese Food Discourse in Major Japanese Newspapers
}

\author{
Isami Omori \\ School of Human Environmental Sciences, \\ Mukogawa Women's University, Hyogo, Japan
}

\begin{abstract}
The aim of this study is to examine the influence of the recent political process, pertaining to the inscription Japanese food (washoku) in the list of Intangible Cultural Heritage by the United Nations Educational, Scientific and Cultural Organization(UNESCO) in 2013 on the food discourse in Japan. The change in the number of articles containing the 3 words for Japanese food, that is, 'nihonshoku', 'nihonryori', and 'washoku', and the appearance frequencies of 50 related words were evaluated in 3 Japanese nation-wide newspapers over a 17-year duration from 2000 to 2016. The appearance ratio of each keyword was analysed for the total number of articles related to Japanese food on a yearly basis. Results showed that the UNESCO inscription triggered a rapid increase in the number of articles related to Japanese food. The highest appearance ratio occurred for the keywords 'taste', and 'heart', in that order. In addition, 'culture', 'heritage', 'world', 'abroad', 'local', and 'tourism' had high appearance ratios following the UNESCO recognition. Ingredients and seasonings such as rice, fish, and soy sauce had higher appearance ratios than menu or course style names such as 'sashimi' and 'kaiseki'. Results indicate that the UNESCO recognition drew Japanese people's attention to Japanese food which was hitherto unseen. This is because the UNESCO registration facilitated a contrast between the characteristics of Japanese food and other international cuisines, which enhanced the attractiveness of Japanese food. In addition, the UNESCO recognition linked words associated with time and place to Japanese food. This political process enabled the propagation of a discourse that emphasized the historical continuity of Japanese food as Japanese 'taste'.
\end{abstract}

Keywords: Japanese food, Cultural Heritage, Food discourse, Time, Place.

\section{INTRODUCTION}

'Washoku, traditional dietary cultures of the Japanese, notably for the celebration of New Year' was added to the Intangible Cultural Heritage list of the United Nations Educational, Scientific and Cultural Organization(UNESCO) in 2013. Washoku is defined as 'a social practice based on a set of skills, knowledge, practice and traditions related to the production, processing, preparation and consumption of food' on UNESCO's list [1]. This occasion hit the headlines of Japanese newspapers. In Japan, newspapers have very high household subscription rates. Japanese national newspapers serve the entire country, for example, Yomiuri Shimbun, which is the largest Japanese newspaper, has the highest circulation worldwide, recording 9.14 copies per day in December 2015. Furthermore, the national newspaper's publishers play a central role in managing mass media groups that gather news reports to provide to their television and radio broadcasters. Therefore, there is significant association between the newspaper article content and social consciousness trends in Japan [2-5].

Several studies have addressed the ambiguity in the definition of Japanese food names and changes in terminology over time. Some examples of such terms include nihonsyoku, nihonryori, and washoku, which are words commonly used by the Japanese in the daily life, and they refer to Japanese cuisine. The Kôjien Japanese dictionary describes nihonryori as 
'traditional Japanese dishes, which have been developed in Japan'. The concept of washoku is vague [6], and the term is generally used as an antonym to western-style food, and to refer to Japanese cuisine after the Meiji era (1868-1912). The Kôjien Japanese dictionary explains that washoku is a 'Japanese style food, namely nihonryori'. Nihonshoku encapsulates a broader concept, referring collectively to nihonryori and washoku. However, the terms nihonshoku, nihonryori, and washoku are used synonymously and interchangeably, and the differences in their meanings are nebulous [7].

Moreover, the registration in UNESCO's cultural heritage list has designated food as a concept of national community and destined cuisine to become a political matter [8]. Hence, the aforementioned definition of washoku was a new political concept created for submission to UNESCO. Indeed, the definition of Japanese food in the application draft was radically revised during the last stages of governmental deliberations. It was changed based on the official definition of 'Gastronomic meal of the French' [9-10]. However, although the political influence on the new concept of washoku was demonstrated, little attention was paid to the shifts in public discourse of Japanese food because of UNESCO's recognition.

This study examines the relationship between the inscription of Japanese food culture in UNESCO's Intangible Cultural Heritage list and the changes evident in Japanese newspaper articles. Our study proposes the hypothesis that the recognition of washoku in UNESCO's list has influenced the description of Japanese food in newspaper articles. We reason that the description of Japanese food would vary with time. In addition, the nomination of Japanese food to UNESCO's list was considered a unique topic, as it was not completely a domestic project. We examine the changes evident in articles containing the three terms for Japanese food, nihonshoku, nihonryori, and washoku published in three nationwide Japanese newspapers from 2000 to 2016. In addition, we evaluated the ratings of 50 related words in these articles. Our hypothesis is that the UNESCO recognition would be reflected in the vocabulary describing food in Japanese newspapers articles, which is simultaneously indicates the trends in discourses on Japanese food.

\section{METHODOLOGY}

The Yomiuri Shimbun, Asahi Shimbun, and Mainichi Shimbun newspapers had a combined household subscription of more than $32 \%$ in 2016. Using paid search engines operated by each newspaper publisher, the contents of these three newspapers were examined from 1 January 2000 through 31 December 2016. Our investigation of keyword frequency trends involved a comparison of the UNESCO registration to a prior political process related to food, the Basic Law on Shokuiku passed in 2005, which institutionalized food and nutrition education. The law intended to increase the awareness of the entire population, including children, regarding food and to promote healthy dietary habits.

Our search found 34,435 articles that containing the terms nihonsyoku, nihonryori, or washoku. We employed 50 keywords collected from the nomination file for the UNESCO list, explanations offered by the Japanese government, results of several polls on food conducted by Yomiuri Shimbun or Mainichi Shimbun [11-13], previous studies on Japanese food [6, 14], and public service announcements related to Japanese cuisine during this period. The keywords were classified into eight categories for use in the analysis, and there was some overlap of keywords within categories (Table 1).

The changes in the number of appearances and relative frequencies of each keyword in all the 34,435 articles were compared before and after occurrence of the UNESCO recognition. 
The descriptive statistics for all the variables in the study were calculated and examined thoroughly before conducting further analyses. The appearance frequency of each keyword was analysed together using cluster analysis. Independent sample t-tests were conducted on the eight categories in order to compare the mean of the keywords' appearance frequency during the pre-UNESCO period (2000-2012) and the post-UNESCO period (2013-2016). Spearman's rho test was used to examine a correlation between the degree of food processing and the appearance frequency percentage of keywords in newspaper articles.

Table 1. Keyword categories and $50^{*}$ keywords.

\begin{tabular}{|c|c|c|}
\hline $\begin{array}{l}\text { from political announcements } \\
\text { anime } \\
\text { certification } \\
\text { chisan-chisyo } \\
\text { (local production for local consumption) } \\
\text { cool Japan } \\
\text { economy } \\
\text { export } \\
\text { self-sufficiency } \\
\text { shokuiku } \\
\text { tourism } \\
\\
\text { from UNESCO list } \\
\text { government explanation) } \\
\text { annual events } \\
\text { bonds (social cohesion) } \\
\text { cooking technique } \\
\text { daily life } \\
\text { eating habits } \\
\text { family } \\
\text { four seasons } \\
\text { health } \\
\text { ichiju-sansai } \\
\text { (one soup and three dishes) } \\
\text { Japanese people } \\
\text { nature } \\
\text { region } \\
\text { social practice } \\
\text { tradition } \\
\text { umami }\end{array}$ & $\begin{array}{l}\text { community } \\
\text { Japanese people } \\
\text { home town } \\
\text { local } \\
\text { nation states } \\
\text { region } \\
\\
\text { food names } \\
\text { dashi (bouillon) } \\
\text { fish } \\
\text { kaiseki } \\
\text { (traditional Japanese multiple course meal) } \\
\text { miso } \\
\text { nikujaga } \\
\text { osechi } \\
\text { ramen } \\
\text { rice } \\
\text { sashimi } \\
\text { soy sauce } \\
\text { sushi }\end{array}$ & $\begin{array}{l}\text { abroad } \\
\text { hometown } \\
\text { local } \\
\text { regional } \\
\text { world } \\
\\
\text { elated times } \\
\text { continuity } \\
\text { heritage } \\
\text { history } \\
\text { tradition } \\
\\
\\
\text { abstract concepts } \\
\text { bonds } \\
\text { culture } \\
\text { heart } \\
\text { hospitality } \\
\text { pride } \\
\text { taste } \\
\text { tradition }\end{array}$ \\
\hline
\end{tabular}

\section{RESULT}

\section{Number of articles on Japanese food}

We first examined whether the UNESCO recognition augmented public interest in Japanese food by scrutinizing the number of newspaper articles on Japanese cuisine for each studied year (Figure 1).

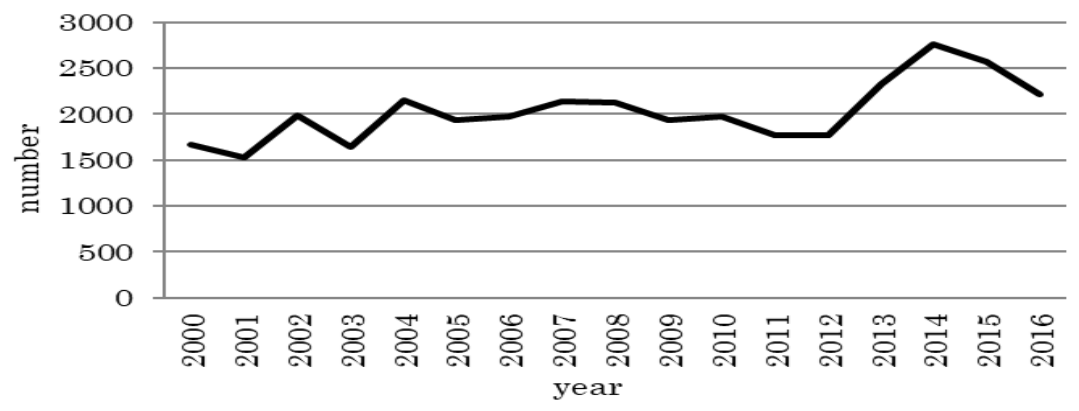

Figure 1. Number of articles on Japanese food. 
Table 2 depicts an increase of $32.9 \%$ in the number of articles on Japanese food from 2000 to 2016. In 2013, the year in which UNESCO inscribed washoku, the number of articles on Japanese food showed the highest growth rate on a year-on-year basis (31.6\%). During 2013 and 2014, the number of articles grew rapidly and reached record high levels. The second highest growth rate of articles on a year-on-year basis (31.4\%) was seen in 2004, which corresponded to the scandal of mislabeling food, pertaining to how some rice producers put labels containing a false place of origin on their rice packing. Contrarily, in 2003, following widespread panic regarding to bovine spongiform encephalopathy, the number of articles dropped by $17.5 \%$ compared to the previous year. Our analyses reveal that the number of articles fluctuated sharply, representing an annual average growth rate of $0.8 \%$ during the period of the study (2000 - 2016). Compared to this, the UNESCO recognition resulted in an increased average growth of $24.9 \%$ from 2012 to 2014. In contrast, the legislation for Shokuiku law (from 2004 to 2006), which saw a decline in articles by $4.2 \%$, had little effect on newspapers articles although there was extensive discussion on Shokuiku in the field of education. This result suggests that the UNESCO recognition had a direct effect on the interest in Japanese food, which was hitherto unseen.

Table 2. Number of times keywords regarding Japanese food appeared in newspaper articles from 1 January 2000 to 21 December 2016*

\begin{tabular}{lrrr}
\hline Year & $\begin{array}{c}\text { Number of } \\
\text { Articles }\end{array}$ & $\begin{array}{c}\text { The Year-on- } \\
\text { Year Growth } \\
\text { Rate }\end{array}$ & $\begin{array}{c}\text { The Annual } \\
\text { Average } \\
\text { Growth Rate }\end{array}$ \\
\hline 2000 & 1666 & - & \\
2001 & 1523 & -0.086 & \\
2002 & 1984 & 0.303 & \\
2003 & 1636 & -0.175 & \\
2004 & 2149 & 0.314 & -0.042 \\
2005 & 1936 & -0.099 & \\
2006 & 1974 & 0.020 & (in 2004-2006) \\
2007 & 2139 & 0.084 & \\
2008 & 2130 & -0.004 & \\
2009 & 1938 & -0.090 & \\
2010 & 1977 & 0.020 & \\
2011 & 1762 & -0.109 & \\
2012 & 1766 & 0.002 & \\
2013 & 2324 & 0.316 & (in 2012-2014) \\
2014 & 2754 & 0.185 & \\
2015 & 2563 & -0.069 & \\
2016 & 2214 & -0.136 & \\
\hline \hline & \multicolumn{4}{c}{1.329} \\
$2000-2016$ & 34435 & (comparison of & \\
& & 2000 and 2016) & \\
*Asahi Shimbun, Yomiuri Shimbun, and Mainichi Shimbun \\
newspapers
\end{tabular}

\section{Change in appearance frequency of keywords before and after the UNESCO registration}

Subsequently, we examined the change of appearance frequencies of keywords in the newspaper articles. The appearance frequency of each keyword was analysed together using a cluster analysis. Additionally, the appearance ratio for the total number of Japanese food articles from 2000 to 2016 was analysed. The keywords that showed the highest ratios, in the decreasing order of magnitude, were 'taste' (42.6\%), 'heart' (37.6\%), and 'rice' (23.3\%). To examine whether the UNESCO recognition influenced the appearance of each keyword, a comparative analysis was conducted to evaluate the data before and after the recognition (Table 3). 
Figure 2 shows that during the study period, clusters were first divided into two groups with the line drawn between the pre-UNESCO period (2000-2012) and the post-UNESCO period (2013-2016).

Across the total number of Japanese food articles, the percentage frequency of 41 keywords in the total number of Japanese food articles increased after the UNESCO recognition period (2013-2016). Among them, the percentage frequencies of six keywords surged by 5 percent or more, including 'culture', 'heritage', 'world', 'abroad', 'region', and 'tourism'. The frequency percentages of eight keywords rose by 3-5 percentage points on average. These were 'tradition', 'export', 'rice', 'taste', 'local', 'dashi', history', and 'economy' (Table 3). On the other hand, the keywords that were used in the nomination file for the UNESCO listing showed lower growth than the overall growth from 2013 to 2016. An independent t-test indicated that there was a significant difference in the differential points of appearance rates for keywords related to 'place' $(\mathrm{M}=5.12, \mathrm{SD}=4.22)$ or not $(\mathrm{M}=1.90, \mathrm{SD}=3.39)$ applying conditions $\mathrm{t}(48)=2.118$, $\mathrm{p}<0.05$, keywords related to 'time' $(\mathrm{M}=6.00, \mathrm{SD}=5.53)$ or not $(\mathrm{M}=1.97, \mathrm{SD}=3.29)$ with conditions $\mathrm{t}(48)=2.23, \mathrm{p}<0.05$. No significant difference was found in keywords such as 'from political announcement', 'from previous study', 'from UNESCO list', 'community', and 'food name' (Table 4). The results confirmed that the UNESCO registration linked the words that are related to time and place with regard to Japanese food.

Table 3. Percentage frequency of each keyword in newspaper articles* on Japanese food.

\begin{tabular}{|c|c|c|c|c|}
\hline \multirow[b]{2}{*}{ Keyword } & \multicolumn{3}{|c|}{ Time Period } & \multirow{2}{*}{$\begin{array}{c}\text { [Change] } \\
\text { Percentage-point } \\
\text { between } \\
\text { pre and post- } \\
\text { UNESCO }\end{array}$} \\
\hline & $\begin{array}{l}2000-2016 \\
(\mathrm{n}=34,435)\end{array}$ & $\begin{array}{l}\text { 2000-2012: } \\
\text { pre-UNESCO } \\
(\mathrm{n}=24,580)\end{array}$ & $\begin{array}{l}\text { 2013-2016: } \\
\text { post-UNESCO } \\
(\mathrm{n}=9,855)\end{array}$ & \\
\hline abroad & 11.3 & 8.8 & 17.6 & 8.7 \\
\hline anime & 1.3 & 0.9 & 2.2 & 1.2 \\
\hline annual events & 0.3 & 0.1 & 0.6 & 0.4 \\
\hline bons & 0.5 & 0.3 & 0.9 & 0.6 \\
\hline certification & 0.9 & 0.6 & 1.6 & 1 \\
\hline chisan-chisyo & 1.5 & 1.5 & 1.7 & 0.2 \\
\hline continunity & 1.4 & 0.9 & 2.7 & 1.8 \\
\hline cooking technique & 0.5 & 0.5 & 0.7 & 0.3 \\
\hline cool Japan & 0.4 & 0.1 & 1.2 & 1.2 \\
\hline culture & 20.0 & 15.3 & 31.9 & 16.6 \\
\hline dairy life & 17.1 & 17.2 & 16.9 & -0.3 \\
\hline dashi & 6.4 & 5.4 & 8.8 & 3.5 \\
\hline eating habits & 0.4 & 0.3 & 0.5 & 0.1 \\
\hline economy & 8.4 & 7.5 & 10.5 & 3 \\
\hline export & 5.7 & 4.4 & 9 & 4.6 \\
\hline family & 16.1 & 15.9 & 16.6 & 0.7 \\
\hline fish & 16.2 & 16.1 & 16.4 & 0.3 \\
\hline four seasons & 2.6 & 2.5 & 2.7 & 0.2 \\
\hline health & 10.0 & 10.2 & 9.4 & -0.8 \\
\hline heart & 37.6 & 37.2 & 38.5 & 1.3 \\
\hline heritage & 5.2 & 1.2 & 15.3 & 14.1 \\
\hline history & 7.4 & 6.4 & 9.9 & 3.4 \\
\hline home town & 3.2 & 3.3 & 2.9 & -0.4 \\
\hline hospitality & 2.9 & 2.2 & 4.7 & 2.5 \\
\hline ichijyu-sansai & 0.6 & 0.3 & 1.2 & 0.9 \\
\hline Japanese people & 10.6 & 10 & 12 & 1.9 \\
\hline kaiseki & 4.9 & 5.4 & 3.8 & -1.6 \\
\hline local & 15.1 & 14.1 & 17.7 & 3.6 \\
\hline miso & 9.1 & 8.8 & 9.9 & 1.1 \\
\hline nation states & 1.7 & 1.5 & 2.2 & 0.7 \\
\hline natural features & 1.1 & 1 & 1.5 & 0.5 \\
\hline nature & 7.9 & 7.8 & 8.2 & 0.4 \\
\hline nikujaga & 0.6 & 0.6 & 0.5 & 0 \\
\hline osechi & 1.1 & 1 & 1.4 & 0.4 \\
\hline pride & 4.2 & 3.6 & 5.6 & 1.9 \\
\hline ramen & 3.3 & 3.1 & 3.9 & 0.9 \\
\hline region & 13.4 & 11.5 & 18 & 6.5 \\
\hline rice & 23.3 & 22.1 & 26.3 & 4.1 \\
\hline sashimi & 5.0 & 5.1 & 4.7 & -0.4 \\
\hline self-sufficiency & 0.7 & 0.7 & 0.5 & -0.2 \\
\hline shokuiku & 2.3 & 2 & 3 & 1 \\
\hline social practice & 0.4 & 0.2 & 0.9 & 0.7 \\
\hline soy source & 7.0 & 6.6 & 8.2 & 1.6 \\
\hline sushi & 9.1 & 9.1 & 9.1 & 0 \\
\hline taste & 42.6 & 41.5 & 45.3 & 3.9 \\
\hline tourism & 11.3 & 9.7 & 15.2 & 5.6 \\
\hline tradition & 10.0 & 8.7 & 13.4 & 4.7 \\
\hline umami & 4.7 & 4.1 & 6.2 & 2.2 \\
\hline world & 18.3 & 15.2 & 26 & 10.7 \\
\hline yoshoku & 7.7 & 8 & 7.1 & -0.9 \\
\hline
\end{tabular}

Asahi Shimbun, Yomiuri Shimbun, and Mainichi Shimbun newspapers 


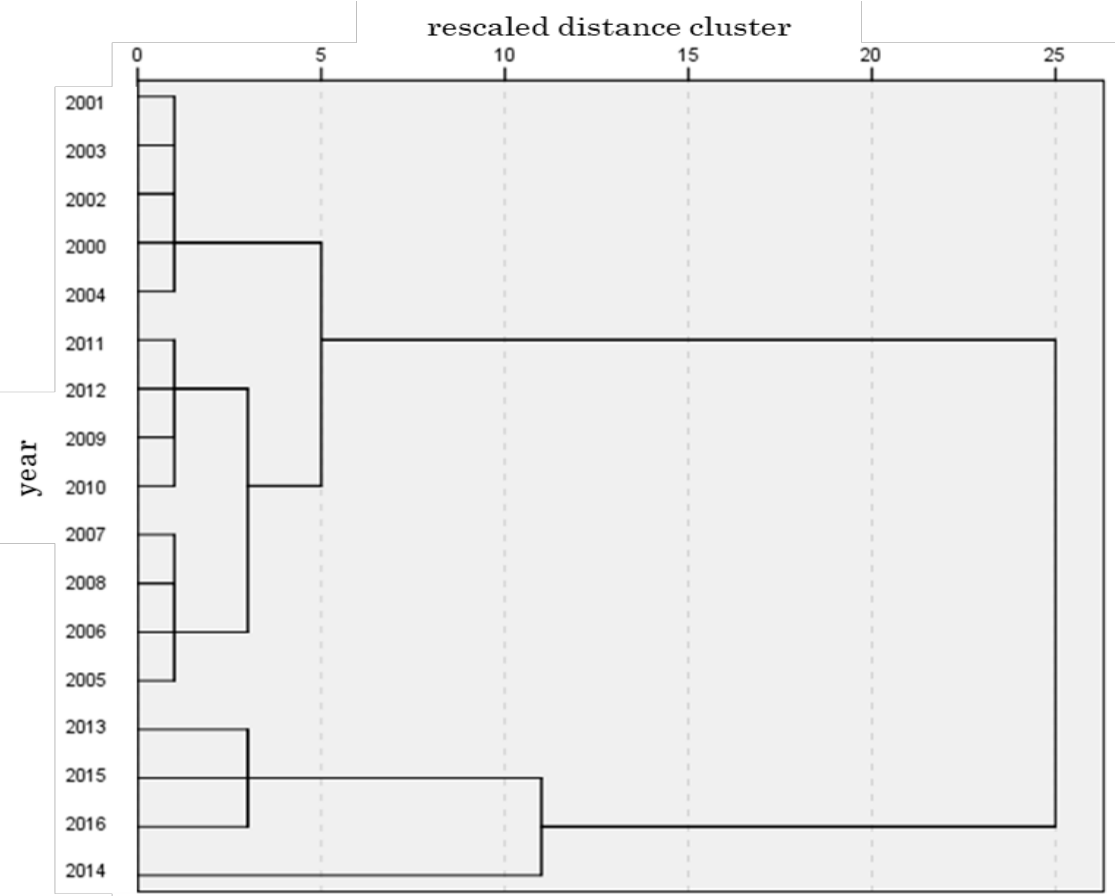

Figure 2. Dendrogram of the years from 2000 to 2016 by 50 appearance frequency of keywords and the average linkage between groups.

Table 4. Associations between keyword categories and percentage-point change in appearance frequency from pre-UNESCO (2000-2012) to post-UNESCO (2013-2016).

\begin{tabular}{|c|c|c|c|c|}
\hline \multirow{3}{*}{ Category } & \multicolumn{2}{|c|}{$\begin{array}{l}\text { Percentage-point/from pre to post UNESCO } \\
\qquad(n=50)\end{array}$} & \multirow[b]{3}{*}{$t$-value } & \multirow[b]{3}{*}{$p(2$-tailed $)$} \\
\hline & Yes & No & & \\
\hline & $(\mathrm{Mean} \pm \mathrm{SD})$ & $($ Mean \pm SD $)$ & & \\
\hline political announcement & $1.96 \pm 2.00$ & $2.36 \pm 3.89$ & -0.30 & $\mathrm{~ns}$ \\
\hline UNESCO list & $1.23 \pm 1.95$ & $2.74 \pm 4.06$ & -1.37 & $\mathrm{~ns}$ \\
\hline previous studies & $1.23 \pm 2.58$ & $2.56 \pm 3.68$ & -0.52 & $\mathrm{~ns}$ \\
\hline community & $2.46 \pm 2.70$ & $2.26 \pm 3.71$ & -1.11 & $\mathrm{~ns}$ \\
\hline food name & $0.90 \pm 1.66$ & $2.68 \pm 3.91$ & -1.46 & $\mathrm{~ns}$ \\
\hline place & $5.12 \pm 4.22$ & $1.90 \pm 3.39$ & 2.12 & $0.04^{*}$ \\
\hline time & $6.00 \pm 5.52$ & $1.97 \pm 3.29$ & 2.23 & $0.03^{*}$ \\
\hline abstract concept & $4.50 \pm 5.52$ & $1.93 \pm 3.14$ & 1.79 & $\mathrm{~ns}$ \\
\hline
\end{tabular}

SD indicates standard deviation

${ }^{*} p<.05{ }^{*}$ Asterisks refer to significance of differences between sample means based on independent sample $t$-test

\section{Appearance frequency percentage of food names by degree of processing}

To further examine the representation of Japanese food conveyed by news stories, we examined the appearance of words signifying the names of actual foods and dishes, classified by the degree to which they had been processed. We used two main criteria to classify levels of processing. First, whether the food can be eaten as it is or used as an ingredient to prepare dishes and second, whether it is composed of one ingredient or several ingredients. We then divided processing degree into 5 ranks of numerically increasing order (Table 5). 
Table 5. Classification according to degree of processing.

\begin{tabular}{lll}
\hline Rank & Category & Food \\
\hline 1 & agricultural or marine products & rice, fish \\
2 & seasoning & soy source, miso \\
3 & bouillon & dashi \\
4 & single dish & nikujaga, ramen, sashimi, sushi \\
5 & meal comprising a plurality of dishes & osechi, kaiseki \\
\hline
\end{tabular}

Figure 3 illustrates that the appearance ratio increases as the meaning of the word indicates partially processed food. Ingredients and seasonings such as 'rice', 'fish', and 'miso' had a higher appearance ratio than menu or course style food names such as 'sashimi', 'nikujaga', and 'osechi'. It is noted that 'nikujaga' is a homemade dish of meat and potatoes braised in sweetened soy source. Further, 'osechi' is a meal 'for the celebration of New Year'. According to polls conducted by Yomiuri Shimbun [12-13], 'sashimi', 'ramen', and 'nikujaga' are popular dishes among Japanese people. We analysed the data using Spearman's rho to discover if there was a correlation between the rank order of processed food and appearance frequency percentage in the keywords that appeared from 2000 to 2016. Based on the results, lessprocessed foods tend to have a higher appearance frequency percentage in newspaper articles ( $\mathrm{rs}=-0.81, \mathrm{p}=0.04<0.01$ ). In addition, a significant correlation was observed between rank order of processed food and the differential points of appearance rates before the UNESCO recognition and after ( $r s=-0.65, \mathrm{p}=0.03<0.01)$.

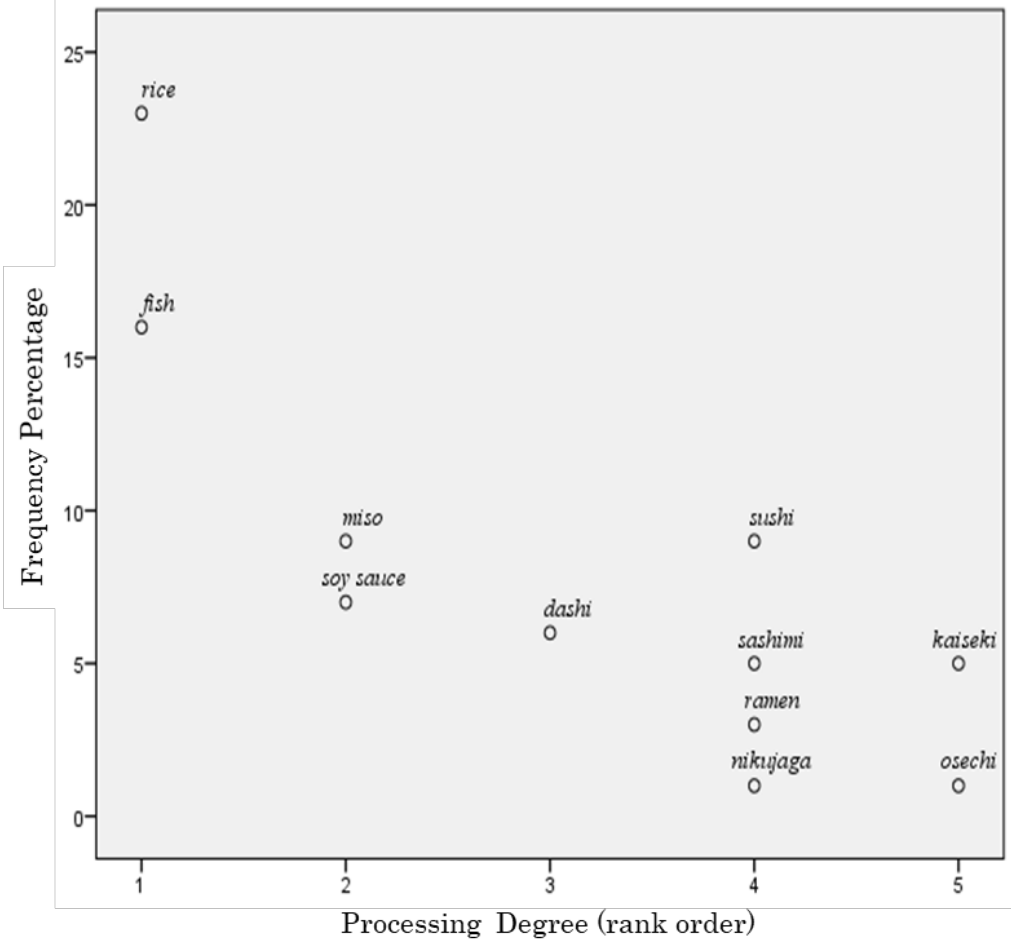

Figure 3. Correlation diagram between the processing degree of food and appearance frequency percentages of keywords

\section{DISCUSSION AND CONCLUSION}

These results significantly contribute to our understanding of the relationship between UNESCO's addition of Japanese cuisine and food culture to its Intangible Cultural Heritage list and Japanese newspaper discourses on food.

First, the number of newspaper articles on the topic of Japanese food rapidly increased after the UNESCO registration in 2013. A similar phenomenon was not witnessed when Shokuiku law, another political initiative, was executed in 2005. 
Second, the most frequently occurring words were 'taste', 'heart', and 'rice'. It has been proposed that rice is not only a staple food of Japanese cuisine, but also closely associated with the Japanese identity and concept of Japan as community, that is, rice is symbol of continuity of the Japanese spirit [15]. Our study revealed that the most frequently used words in newspaper articles were those that reminded readers of the community cultural identity of Japanese people.

Third, the trend of appearance frequencies of keywords changed from the pre-UNESCO period (2000-2012) to the post-UNESCO period (2013-2016). Furthermore, the difference in the changes among keywords was associated with strong connotations of time and place. Specific examples include the words 'world' and 'abroad', which showed rapid growth.

Finally, we demonstrated that there was no significant difference in appearance frequencies of specific food names directly related to the UNESCO recognition. During the complete period (2000-2016), minimally processed foods had a greater frequency of appearance in newspaper articles.

These results suggest that the unique characteristics of Japanese food were enhanced by contrasting it with international cuisines, which was emphasized by the registration to the UNESCO list. In the characterization of Japanese food after the registration, time and place were critical elements rather than specific foods. This indicates that abstract words that could evoke nostalgia, such as 'taste', 'tradition', and 'local', were used more often than heuristic words, such as 'cooking techniques' or 'nikujaga', which was the most common home-cooked Japanese dish according to several polls. Based on our results, we conclude that newspaper discourses created and shared a representation of Japanese food that could be proudly presented to the 'world'.

Several previous studies have investigated the attachment of taste to place as one of the tautologies of food and identity [16-17]. On the other hand, with the spread of globalization, national boundaries are blurring, even with regard to food, and the intersections of practices and information regarding food are becoming de-territorialized and multi-referential. The framework of the nation-state is becoming increasingly relative [18].

The Japanese food (washoku), which was nominated for inscription on UNESCO's list of Intangible Cultural Heritage, is considered to be an attempt to create a new construct of national food in response to globalization. The results of our study demonstrate that after the UNESCO recognition, keywords related to time and place were frequently used in newspaper articles to evoke nostalgia. Furthermore, there was an increased frequency of appearance in keywords related to less-processed foods that typified shared experiences among many people.

In conclusion, this study demonstrated that the UNESCO recognition triggered a rapid increase in the number of newspapers articles on the topic of Japanese food. In other words, the UNESCO recognition drew Japanese people's attention to Japanese cuisine like never before. The primary focus of the articles published after the UNESCO recognition was on the continuity and endemism of Japanese food. This political process reinforced the authority of Japanese newspaper discourses on Japanese food. The trends revealed by the appearance frequencies of keywords in the emphases on and propagations of Japanese food as the memories of Japan as a country are striking. However, these trends do not accurately reflect the characteristics of Japanese cuisine. 
Further studies are warranted in order to specify the period of the effect of UNESCO's recognition and subsequent changes. We expect that further characterization of the changing descriptions of Japanese food will yield critical insights that will help facilitate discussions about the relationship between politics and food culture.

\section{References}

UNESCO. Intangible Cultural Heritage. (n.d.). https://ich.unesco.org/en/RL/washoku-traditional-dietarycultures-of-the-japanese-notably-for-the-celebration-of-new-year-00869. Accessed 18 August 18, 2017.

Dentsu, Information Media Trend in Japan: 2016 Information White Paper. .

Higuchi, K., Contemporary National Newspapers and Social Consciousness: Efficiency and Limitations of Newspaper Content Analysis. Kodo Keiryogaku 2011.74: p.1-12.

Kashiwakura, Y., Mass Media no Genzai, in Nihon no Mass Media, Y. Kashiwakura, Editor 2007. p. 9-15., Hosodaigaku Kyoiku Shinkokai: Tokyo, JAPAN.

Mizukoshi, S., 21 Seiki Media-ron. 2011, Hosodaigaku Kyouiku Shinkokai: Tokyo, JAPAN.

Harada, N., Washoku to Nihonbunka: Nihonryori no Syakaishi, 2005, Shogakukan: Tokyo, JAPAN.

Kashiwagi, K., Globalized Japanese Food: A Consideration of the Japanese Food Boom in Germany. Intercultural, 2012. 10: p.161-178.

Tornatore, J., Anthropology's Payback: The Gastronomic Meal of the French, in The Ethnographic Elements of a Heritage Distinction, Heritage Regimes and the State, R. Bendix, A. Eggert and A. Peselmann, Editor 2013. p. 341364.

Cang, V., Unmaking Japanese Food: Washoku and Intangible Heritage Designation. Food Studies, 2015. 4(3): p.4958.

Omori, I., The Redefinition of Washoku as National Food: Food Politics and National Identity in Japan. International Journal of Social Science and History, 2017. 7(12): p.729-734.

Study finds free care used more. Mainichi Shimbun, 2004. March 5: p.12.

Study finds free care used more. Yomiuri Shimbun, 2005. April 29: p.25.

Study finds free care used more. Yomiuri Shimbun, 2013. December 23: p.17.

Kumakura, I., Nihonryori Bunkashi: Kaiseki wo Chushin ni, 2002, Jimbun Shoin: Kyoto, JAPAN.

Ohnuki-Tierney, E., Rice as self: Japanese identities through time, 1995, Princeton University Press: Princeton, NJ, USA.

Sutton, D., Cooking Skills, the Senses, and Memory: The Fate of Practical Knowledge, in Sensible objects: colonialism, museums, and material culture, E. Edwards, C. Gosden and R. B. Phillips, Editor 2006. P. 87-120., Berg: Oxford, UK.

Sutton, D., Food and the Senses. Annual Review of Anthropology 2010. 39(1): p.209-223.

Nonini, D. M., 2013. The local-food movement and the anthropology of global systems. American Ethnologist 2013.40(2): p.267-275. 